\title{
Lidil
}

Revue de linguistique et de didactique des langues

$44 \mid 2011$

Langues, minor(is)ations et marginalisations

\section{Bruno Maurer, Enseignement des langues et construction européenne - Le plurilinguisme, nouvelle idéologie dominante}

Éditions des Archives Contemporaines, Paris, 2011

Marielle Rispail

\section{OpenEdition}

Journals

Édition électronique

URL : http://journals.openedition.org/lidil/3161

DOI : $10.4000 /$ lidil.3161

ISSN : $1960-6052$

Éditeur

UGA Éditions/Université Grenoble Alpes

Édition imprimée

Date de publication : 15 décembre 2011

Pagination : 148-151

ISBN : 978-2-84310-212-7

ISSN : $1146-6480$

\section{Référence électronique}

Marielle Rispail, « Bruno Maurer, Enseignement des langues et construction européenne - Le

plurilinguisme, nouvelle idéologie dominante », Lidil [En ligne], 44 | 2011, mis en ligne le 15 juin 2013,

consulté le 24 septembre 2020. URL : http://journals.openedition.org/lidil/3161 ; DOI : https://doi.org/ 10.4000/lidil.3161 


\section{Note de lecture}

Bruno Maurer, Enseignement des langues et construction européenne - Le plurilinguisme, nouvelle idéologie dominante, Paris, Éditions des Archives Contemporaines, 2011, 156 p.

Il fallait bien que quelqu'un s'y colle, Bruno Maurer l'a fait.

Le consensus devrait faire peur, bien sûr dans la critique qui détruit, mais aussi quand les louanges sont trop unanimes. Car le consensus n'est pas loin de la voie (voix ? c'est facile...) unique. Bruno Maurer a décidé de regarder ce qu'il y avait derrière ces « compétences plurilingues et interculturelles », qui rassemblent de plus en plus de voix, venues d'Europe et d'ailleurs. Car, souligne-t-il, il ne faut pas oublier que ces refrains à entonner en chœur répondent à une commande du Conseil de l'Europe : on peut donc se demander légitimement à quelle idéologie ou quel projet de société elles répondent, dont la préoccupation ne serait peut-être pas essentiellement didactique.

Autrement dit, Bruno Maurer se demande : à travers ces textes qui circulent sur l'enseignement des langues, apparemment inattaquables à force de bonne volonté et de générosité civiques, quelle société veut-on «nous vendre »? Et de démonter fil à fil le processus de production de ces textes européens, à partir de questions fondamentales qui font de l'ouvrage un triptyque bien d'aplomb sur ses pattes :

- de quoi est fait ce nouveau paradigme de l'Éducation en Europe?

- et si, derrière cette « éducation nouvelle », se profilait et se diffusait une nouvelle idéologie qui ne dit pas son nom?

- et si c'était l'Europe plus que la vie des langues qui était l'objectif de cette construction d'apparence didactique?

C'est ainsi que les 3 parties qui le structurent s'intitulent :

- L'Éducation plurilingue et interculturelle : le nouveau paradigme de l'éducation en Europe;

- De quoi l'éducation plurilingue et interculturelle est-elle le nom? Production et diffusion d'une idéologie;

- Rôle de l'idéologie plurilingue dans la construction de l'Europe. 
Bien sûr, la démarche est provocante, elle est pourtant rigoureuse et documentée (l'auteur est allé fureter dans bien des recoins de l'Europe et de ses textes) et relève bien de l'attitude d'un chercheur : celle de questionner nos évidences, essence de la posture scientifique dont notre collègue J.-P. Bronckart a dit (Donostia, 1999) qu'elle consiste à savoir « scier la branche sur laquelle on est assis ». Il s'agit moins de critiquer des contenus en tant que tels que de mettre au jour ce qu'ils nous cachent. Maurer semble ainsi dire qu'à nous faire discuter sur des miroirs aux alouettes certes passionnants (quel plurilinguisme, à bas le monolinguisme, enseignement ou éducation, quelles compétences, etc.), on nous détourne de questions qui, sans être plus fondamentales, devraient peut-être se poser en amont : quelles valeurs promouvoir, de quoi est fait l'humanisme européen, relation entre diversité et tentation universaliste, que faire des phénomènes de minoration, comment se lient langues et sentiments identitaires, etc.

Ce mouvement amène l'auteur à s'inquiéter (et nous inquiéter), dans le sens fort de "perdre sa tranquillité », à propos de quelques points sensibles sur lesquels il appuie intentionnellement :

- le texte du CECR, présenté comme référence unique, est-il un texte de recherche ou un texte politique? partant, quel est le statut de ses auteurs?

- quelle vision de la démocratie est à lire derrière ces déclarations ? et en particulier, comment y sont traitées la diversité et les minorités?

- de l'enseignement à l'éducation : et les langues dans tout ça ?

- ne peut-on déceler quelques échos troubles entre le pluri- et l'interrendant nos futurs travailleurs européens déplaçables et le libéralisme qui a besoin d'une « mobilité accrue » dans le monde du travail?

Citons l'auteur, pour terminer, à travers quelques extraits de sa conclusion. Il résume son interrogation dans un paradoxe de départ : «aucun régime politique n'a sans doute affirmé avec autant de force que l'Europe l'importance du plurilinguisme de ses citoyens... d'un autre côté, si les programmes de l'éducation plurilingue se réalisent, jamais peutêtre on n'aura si peu enseigné les langues elles-mêmes. Comment en est-on arrivé là ? » et fait l'hypothèse que le texte du CECR fait peutêtre partie d'un dispositif visant à répondre à un "déficit de citoyenneté » en Europe, qui se manifesterait entre autre par la «montée des extrémismes », des «attitudes xénophobes » et de possibles conflits qui mettraient à mal la «cohésion sociale » visée : «En misant tout sur 
l'ouverture à l'altérité, la sensibilisation à l'interculturel, elle cherche à prévenir les tensions ou les conflits que pourrait générer la coexistence de 27 nations au sein d'un ensemble politique qui n'entend pas se donner de projet politique fédérateur. » On peut alors se demander avec lui si «le plurilinguisme tient lieu d'élément fondateur en quelque sorte ou, du moins, (si) on cherche à lui faire tenir cette fonction ». Qu'on ne s'étonne pas, dans ces conditions, que l'apprentissage des langues (qu'on l'appelle «méthode communicative » ou autrement) devienne « secondaire dans les parcours proposés aux élèves ». Sans nier l'intérêt des intentions ci-dessus, Maurer se dit qu'au moins, on pourrait en discuter et que " par ce livre, (il espère) commencer à ouvrir le débat au sein de la communauté des chercheurs, afin que les tenants et les aboutissants, les motivations et les effets, soient clairement connus de tous ».

Vous avez dit plurilingue? Merci Bruno.

Marielle Rispail CEDICLEC, Université Jean Monnet - St-Étienne LIDILEM, Université de Grenoble 